\title{
Efficacy and safety of TAS-115, a novel oral multi-kinase inhibitor, in osteosarcoma: an expansion cohort of a phase I study
}

\author{
Akira Kawai ${ }^{1}$ (1) - Norifumi Naka ${ }^{2} \cdot$ Akihiko Shimomura $^{3,4} \cdot$ Shunji Takahashi $^{5} \cdot$ Shigehisa Kitano $^{6,7,8}$. \\ Yoshinori Imura ${ }^{2} \cdot$ Kan Yonemori $^{3} \cdot$ Fumihiko Nakatani $^{1}$. Shintaro Iwata ${ }^{1}$. Eisuke Kobayashi ${ }^{1} \cdot$ Hidetatsu Outani $^{9}$. \\ Hironari Tamiya ${ }^{2} \cdot$ Yoichi Naito $^{10} \cdot$ Noboru Yamamoto $^{6} \cdot$ Toshihiko Doi $^{11}$
}

Received: 4 January 2021 / Accepted: 22 March 2021 / Published online: 12 June 2021

(C) The Author(s) 2021

\section{Summary}

Background osteosarcoma is a rare, primary malignant bone tumour with limited available treatments for advanced or recurrent disease, resulting in a poor prognosis for patients. TAS-115 is a novel tyrosine kinase inhibitor under investigation in a phase I study in patients with solid tumours. We report data of osteosarcoma patients in the expansion cohort of this ongoing study. Patients and methods an analysis of this multicentre, open-label study was performed 6 months after the final patient was enrolled, and included patients aged $\geq 15$ years, with unresectable or recurrent osteosarcoma, and who had refractory to standard therapy or for whom no standard therapy was available. TAS- $115650 \mathrm{mg} /$ day was orally administered in a 5 days on/2 days off schedule. Results a total of 20 patients with osteosarcoma were enrolled. The most common adverse drug reactions (ADRs) were neutrophil count decreased (75\%), aspartate aminotransferase increased (50\%), and platelet count decreased (50\%); $85 \%$ of patients had grade $\geq 3$ ADRs. Long-term disease control ( $>1$ year) with TAS-115 was achieved in three patients. The best overall response was stable disease (50\%); no patient achieved a complete or partial response. Median progression-free survival was 3 months; 4-month and 12-month progression-free rates were $42 \%$ and $31 \%$, respectively. Conclusion the safety and tolerability of TAS-115 and long-term disease stability for patients with unresectable or recurrent osteosarcoma were confirmed in this study, suggesting that TAS-115 is a promising novel therapy for advanced osteosarcoma patients. Trial registration number: JapicCTI132333 (registered on November 8, 2013).

Keywords TAS-115 $\cdot$ Multi-kinase inhibitor $\cdot$ McDonough feline sarcoma $\cdot$ Met proto-oncogene $\cdot$ Vascular endothelial growth factor receptor - Osteosarcoma

Akira Kawai

akawai@ncc.go.jp

1 Department of Musculoskeletal Oncology and Rehabilitation, National Cancer Center Hospital, 5-1-1 Tsukiji, Chuo-ku, Tokyo 104-0045, Japan

2 Musculoskeletal Oncology Service, Osaka International Cancer Institute, Osaka, Japan

3 Department of Breast and Medical Oncology, National Cancer Center Hospital, Tokyo, Japan

4 Department of Breast and Medical Oncology, National Center for Global Health and Medicine, Tokyo, Japan

5 Department of Medical Oncology, The Cancer Institute Hospital of JFCR, Tokyo, Japan
6 Experimental Therapeutics, National Cancer Center Hospital, Tokyo, Japan

7 Present address: Experimental Therapeutics, National Cancer Center Hospital, Tokyo, Japan

8 Present address: Division of Cancer Immunotherapy Development, The Cancer Institute Hospital of JFCR, Tokyo, Japan

9 Department of Orthopaedic Surgery, Osaka University Graduate School of Medicine, Osaka, Japan

10 Department of Experimental Therapeutics/Breast and Medical Oncology, National Cancer Center Hospital East, Kashiwa, Japan

11 Department of Gastrointestinal Oncology, National Cancer Center Hospital East, Kashiwa, Japan 


\section{Introduction}

Osteosarcoma is a rare, primary bone malignancy, with a worldwide annual incidence of 3.4 million [1]. Despite being rare, osteosarcomas are the most common primary bone tumour in children and adolescents; the incidence peaks during the 20s [2]. Current therapy aims to prevent microscopic metastasis and comprises local surgery and neoadjuvant/adjuvant chemotherapy [3], namely, high-dose methotrexate, doxorubicin, and cisplatin (MAP) [4]. However, no effective treatment for osteosarcoma patients after MAP treatment has yet been confirmed.

The 5-year survival rate for patients with advanced osteosarcoma is $\sim 62 \%$ [1]. About $20 \%$ of patients have metastases at the time of diagnosis [5], with an estimated survival rate of $20 \%$ [6]. Bone and pulmonary metastases are prognostic factors of poor survival $[2,5]$; pulmonary metastases are more common (80\%) [5].

No new drugs have been approved since the 1980s, except for mifamurtide (EU approval in 2009) [7]. In a pooled data analysis, the rate of recurrence-free survival in 96 patients with advanced or recurrent osteosarcoma was $12 \%$ at 4 months [8]. In a study in Japanese osteosarcoma patients with pulmonary metastases [9], most patients with inoperable disease died within 1 year. Thus, the unmet need for osteosarcoma treatment is high.

Although various factors (such as vascular endothelial growth factor [VEGF], insulin-like growth factor 1, plateletderived growth factor [PDGF], human epidermal growth factor receptor 2, and hepatocyte growth factor receptor [MET]) overexpressed in osteosarcoma tumour cells have been suggested as therapeutic targets [10], no targeted agents, including kinase inhibitors, have yet been approved for this condition. This is attributed to the rarity and genetic heterogeneity of osteosarcoma [3]. However, multi-targeted tyrosine kinase inhibitors are reportedly effective in osteosarcoma. A Phase II study of regorafenib (which targets the VEGF receptor [VEGFR], PDGF receptor [PDGFR], fibroblast growth factor receptor, angiopoietin receptor TIE2, and the proto-oncogenes KIT, RET, RAF-1, and BRAF) in adults with metastatic osteosarcoma reported a median progression-free survival (PFS) of 16.4 weeks (95\% confidence interval [CI] 8.0-27.3) in the regorafenib group and 4.1 weeks $(3.0-5.7)$ in the placebo group [11]. A Phase II study of cabozantinib (which targets VEGFR-2, the AXL receptor tyrosine kinase, and c-MET) in 42 patients with heavily pretreated, advanced osteosarcoma reported a median PFS of 6.2 months [12].

TAS-115, a novel oral multi-kinase inhibitor, inhibits the autophosphorylation of MET, VEGFR, PDGFR, and Feline McDonough Sarcoma oncogene [13, 14]. In non-clinical osteosarcoma studies, TAS-115 inhibited tumour enlargement and progression of pulmonary metastasis [13], demonstrating its potential antitumour effects at lung metastatic tumour sites. A Phase I study aimed to evaluate TAS-115 treatment for advanced solid tumours is ongoing [15]. Based on the efficacy of TAS-115 among patients with bone lesions in parts 1 and 2 [15], osteosarcoma patients were enrolled in the expansion cohort of the study. Herein, we report the safety and efficacy results of osteosarcoma patients treated with TAS-115 in the expansion cohort.

\section{Methods}

\section{Study design}

The study design was previously reported [15]. Briefly, this multicentre, open-label, dose-titration study centrally enrolled patients with solid tumours, was initiated on December 1, 2013, and is ongoing. Analyses were prespecified (Supplementary Methods). Here, we report the analysis performed 6 months after the final patient was enrolled (data cutoff: August 19, 2018).

The study has three parts: a dose-escalation cohort using a traditional $3+3$ design (part 1), a dosing schedule investigation cohort (part 2), and an expansion cohort to assess the safety at the maximum tolerated dose (MTD) or lower doses among additional patients (expansion part) (Supplementary Figure 1). In the expansion part, after the MTD was determined, an additional safety and efficacy investigation was performed using a dose $\leq$ MTD based on the development of adverse drug reactions (ADRs) and pharmacokinetic data.

The study protocol was approved by the institutional review board at each participating site and was conducted per the ethical principles of the Declaration of Helsinki, Pharmaceutical Affairs Law, and Good Clinical Practice. All patients provided written informed consent [15].

\section{Patients}

Complete inclusion/exclusion criteria are provided in the Supplementary Methods. Briefly, eligible patients were aged $\geq 15$ years and had osteosarcoma refractory to standard therapy or for which no appropriate standard therapy was available, Eastern Cooperative Oncology Group performance status (ECOG PS) 0 or 1, and adequate bone marrow reserve and renal and liver function at enrolment. Exclusion criteria included serious medical conditions, surgery within 28 days of enrolment, and radiation therapy or other anticancer therapy within 21 days of enrolment.

\section{Treatment}

The treatment regimen comprised TAS- $115650 \mathrm{mg} /$ day, orally administered in a 5 days on/ 2 days off schedule. If patients met any of the following criteria, TAS- 115 treatment was discontinued: neutrophil count $<500 / \mathrm{mm}^{3}$, platelet count $<50,000 / \mathrm{mm}^{3}$, grade $\geq 3$ nonhaematologic toxicity, and any 
Table 1 Patient baseline demographic and clinical characteristics

\begin{tabular}{ll}
\hline Baseline characteristics & $N=\mathbf{2 0}$ \\
\hline Age, years & $30(16-64)$ \\
$\quad$ Median (range) & \\
Sex, $n(\%)$ & $12(60) / 8(40)$ \\
Female / Male & \\
ECOG PS, $n(\%)$ & $13(65) / 7(35)$ \\
$0 / 1$ & \\
Primary lesion, $n(\%)$ & $2(10 \%)$ \\
Yes & $18(90 \%)$ \\
No & \\
Prior treatment regimen, $n(\%)$ & $18(90)$ \\
Regimen equivalent to MAP & \\
Number of other regimens received & $1(5)$ \\
0 & $7(35)$ \\
1 & $7(35)$ \\
2 & $5(25)$ \\
$\geq 3$ & \\
Site(s) of metastasis, $n(\%)$ & $8(40)$ \\
Lung & $5(25)$ \\
Lung and bone & $4(20)$ \\
Bone & $3(15)$ \\
Other (except for lung or bone) & \\
\hline
\end{tabular}

ECOG PS Eastern Cooperative Oncology Group Performance Status, $M A P$ methotrexate, doxorubicin, and cisplatin

other toxicity at the investigator's discretion. Criteria for TAS115 dose reductions, treatment resumption, precautions, and prohibited concomitant medications and therapies are provided in the Supplementary Methods.

\section{Procedures and assessments}

Examinations included body weight and vital signs, laboratory tests, electrocardiogram, tumour bone markers, bone metabolism markers, and ECOG PS assessment. Imaging tests (e.g., computed tomography $[\mathrm{CT}]$, magnetic resonance imaging, bone scintigraphy, positron-emission tomography [PET], and radiographs) were performed before enrolment. Using Day 1 of cycle 1 as baseline, imaging tests were performed on Days 42 and 84, and subsequently, every 84 days. Bone scintigraphy was performed to assess metastasis. BONENAVI ${ }^{\circledR}$ software was used to calculate the bone scan index (BSI).

\section{Endpoints}

Adverse events (AEs) and ADRs were recorded and graded according to the Common Terminology Criteria for Adverse Events (CTCAE version 4.03). Efficacy was based on response evaluated by imaging and antitumour effect assessed according to the Response Evaluation Criteria in Solid Tumors (RECIST version 1.1). Efficacy endpoints were overall response, best overall response, PFS, and disease control rate (DCR). PFS was the period from enrolment to the confirmation date of disease progression or death by any cause before the completion date of the post-observation period, whichever occurred first. DCR was defined as the percentage of patients whose best overall response was complete or partial response (CR/PR) or who continued to have stable disease (SD) for $\geq 12$ weeks. Bone scan response was based on BSI.

\section{Statistical methods}

In this subgroup analysis of the main study population, no statistical rationale was applied to calculate the sample size. The response rate, disease control rate, and corresponding 95\% CIs were calculated based on best overall response. PFS was estimated using the Kaplan-Meier method. All statistical processing was performed using SAS Version 9.4.

\section{Results}

\section{Patients}

Of 55 patients enrolled in the expansion cohort from five sites, 20 had osteosarcoma and were included in this analysis.

Table 2 Adverse drug reactions of any grade with an incidence of $\geq 20 \%$

\begin{tabular}{lllll}
\hline Preferred term, $\boldsymbol{n}(\boldsymbol{\%})$ & G1 & $\mathbf{G 2}$ & $\mathbf{Z G 3}$ & Total \\
\hline Neutrophil count decreased & 0 & $3(15)$ & 12 & $15(75)$ \\
Platelet count decreased & $4(20)$ & $2(10)$ & $4(20)$ & $10(50)$ \\
Aspartate aminotransferase increased & $7(35)$ & $1(5)$ & $2(10)$ & $10(50)$ \\
White blood cell count decreased & 0 & $2(10)$ & $7(35)$ & $9(45)$ \\
Face oedema & $7(35)$ & $2(10)$ & 0 & $9(45)$ \\
Alanine aminotransferase increased & $4(20)$ & $3(15)$ & $1(5)$ & $8(40)$ \\
Hypophosphataemia & 0 & $2(10)$ & $5(25)$ & $7(35)$ \\
Anaemia & 0 & $2(10)$ & $3(15)$ & $5(25)$ \\
Rash & $2(10)$ & $2(10)$ & $1(5)$ & $5(25)$ \\
Pyrexia & $2(10)$ & $2(10)$ & $1(5)$ & $5(25)$ \\
Nausea & $4(20)$ & $1(5)$ & 0 & $5(25)$ \\
Diarrhoea & $5(25)$ & 0 & 0 & $5(25)$ \\
Blood creatine phosphokinase & $2(10)$ & $1(5)$ & $1(5)$ & $4(20)$ \\
$\quad$ increased & $2(10)$ & $2(10)$ & 0 & $4(20)$ \\
Lipase increased & $3(15)$ & 0 & $1(5)$ & $4(20)$ \\
Amylase increased & $3(15)$ & $1(5)$ & 0 & $4(20)$ \\
Fatigue & $4(20)$ & 0 & 0 & $4(20)$ \\
Blood lactate dehydrogenase increased & & & & \\
\hline
\end{tabular}

$G$ Grade 
Fig. 1 Progression-free survival of patients with osteosarcoma. CI, confidence interval; PFR, progression-free rate; PFS, progression-free survival

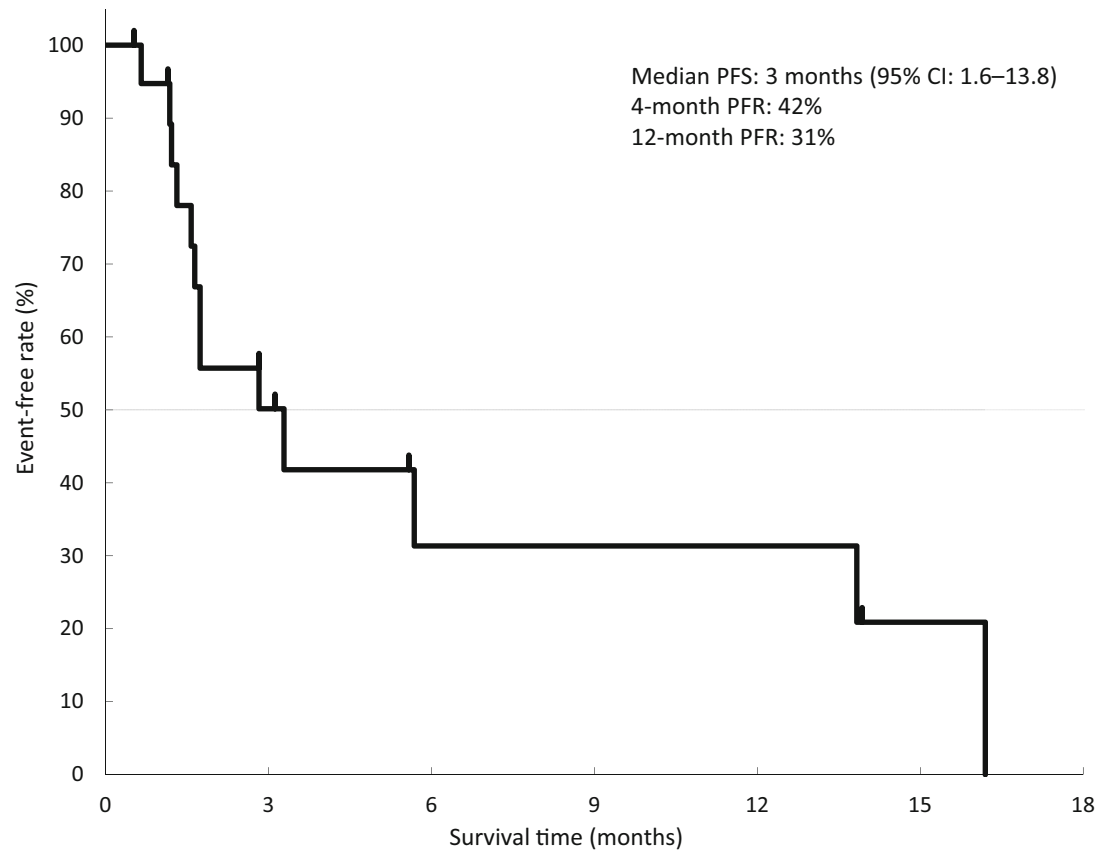

Baseline demographic and clinical characteristics of osteosarcoma patients are shown in Table 1. Patients had a median age of 30 years; $90 \%$ did not have a primary lesion. Most patients (90\%; $n=18)$ had previously received a regimen equivalent to MAP. Of patients who had received prior therapies other than MAP, $35 \%(n=7)$ each had received one and two treatment regimens and $25 \%(n=5)$ had received $\geq 3$ regimens. The most common metastasis site was lung $(40 \% ; n=8)$, with $25 \%(n=5)$ presenting with both lung and bone metastases.

\section{Safety}

The overall incidence of grade $\geq 3$ ADRs $(\geq 10 \%)$ was $85 \%$ $(n=17)$; the most common were neutrophil count decreased, white blood cell count decreased, hypophosphataemia, and anaemia (Table 2). Common ADRs occurring at an incidence

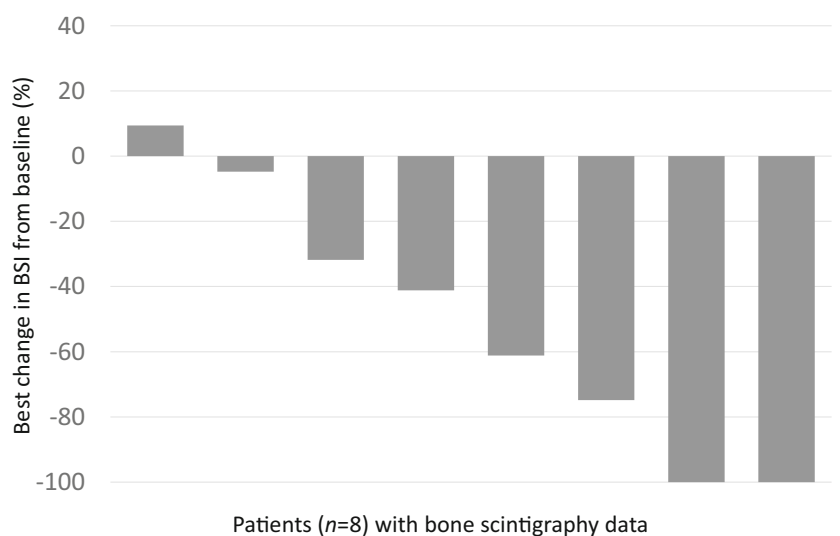

Fig. 2 Bone scan response from baseline by BSI (Waterfall plot). BSI, bone scan index
$>30 \%$ were neutrophil count decreased, aspartate aminotransferase increased, platelet count decreased, white blood cell count decreased, face oedema, alanine aminotransferase increased, and hypophosphataemia. Serious AEs are described in the Supplementary Results and Supplementary Table 1.

Fig. 3 Summary and radiographic images of three individual patient cases. a Case \#5. Female patient with primary osteosarcoma lesion in the fibula and metastases to the lungs and bone initiated TAS- 115 treatment at $650 \mathrm{mg} /$ day. After 3 weeks, the dosing level was reduced to $450 \mathrm{mg} /$ day owing to bone marrow suppression. A further dose reduction to $300 \mathrm{mg}$ /day was decided at 12 weeks owing to neutropenia. Although CT imaging at 24 weeks showed new multiple pulmonary nodules and indicated progressive disease, TAS- 115 treatment continued with incremental dosing increases to $450 \mathrm{mg} /$ day. CT imaging after 36 weeks showed shrinkage of the pulmonary nodules. b Case \#2. Male patient with primary osteosarcoma lesion in the femur and metastases to the lungs started TAS- 115 treatment at a dose of $650 \mathrm{mg} /$ day and showed a significant response to treatment by bone scintigraphy. As the patient presented with grade 3 neutrophil count decreased in cycle 1, the dose was decreased to $450 \mathrm{mg}$ /day from cycle 2 onwards. The patient remained in SD for a long period. On Day 429, the patient had a bone fracture secondary to a misstep. TAS- 115 administration was stopped owing to bone fracture treatment. On Day 491, the patient discontinued the study because a new neoplasm was observed via CT; pulmonary metastasis was enlarged, and a large amount of pleural fluid was observed. c Case \#19. Female patient with primary osteosarcoma lesion in the humerus and metastases to the lungs, bones, and lymph nodes showed signal reduction of the left thoracic and left rib metastasis by PET-CT at 6 weeks. However, the patient discontinued treatment due to rash at 1 week. ADR, Adryblastin ${ }^{\circledR}$ (doxorubicin); AI, Adryblastin ${ }^{\circledR}$ (doxorubicin and ifosfamide; ALP, alkaline phosphatase; BAP, bone alkaline phosphatase; CDDP, cisplatin; DTX, docetaxel; GD, gemcitabine and docetaxel, GEM, gemcitabine; IFO, ifosfamide; LN, lymph nodes; MTX, metothrexate; PD, progressive disease; PET-CT, Positron Emission Tomography/Computed Tomography; TRACP, tartrate resistant acid phosphatase; VP-16, etoposide 
a Sex: Female Prior therapy

\#5 Age: 47

$<1>$ (Neoadjuvant) MTX/CDDP/ADR: 154 days

Primary lesion: Fibula $\quad<2>$ (Adjuvant) MTX/CDDP/ADR/IFO/VP16: Unknown Metastatic lesion: Lungs, bone <3> GEM+DTX: Unknown

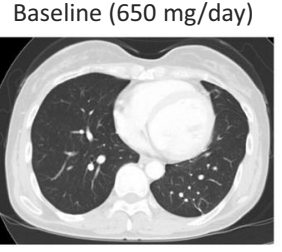

48 weeks ( $450 \mathrm{mg} /$ day)

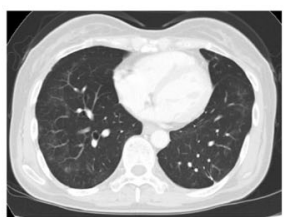

24 weeks (300 mg/day)

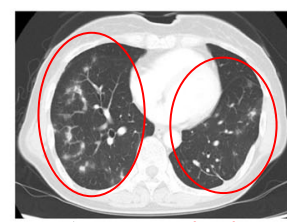

1 New multiple pulmonary nodules

60 weeks ( $450 \mathrm{mg} /$ day)

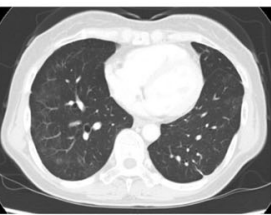

36 weeks (450 mg/day)
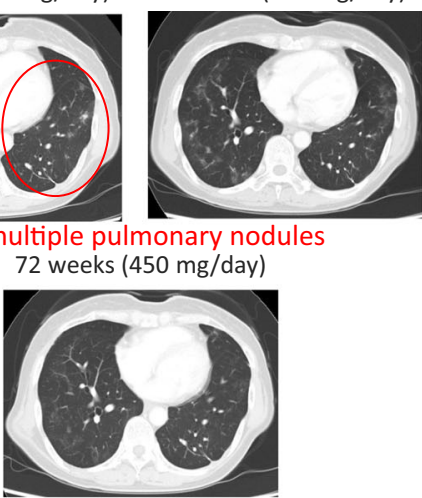

b
\#2 Sex: Male
Prior therapy
Age: $47 \quad<1>$ (Neoadjuvant) ADR/IFO: 46 days
Primary lesion: Femur $<2>$ (Adjuvant) ADR/IFO: 26 days

Metastatic lesion: Lung <3> GEM+DTX: 90 days

\begin{tabular}{ll|l|l|l|l|} 
Resection of the right femoral \\
proximal osteosarcoma \\
Day 325
\end{tabular}

Target Lesion, Right lower lobe of lung (S10)
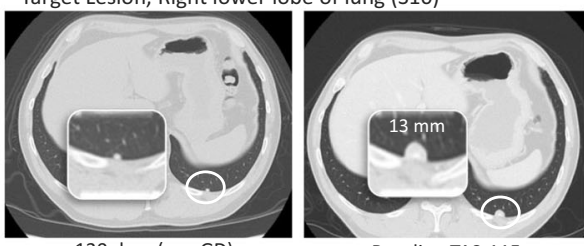

Baseline TAS-115
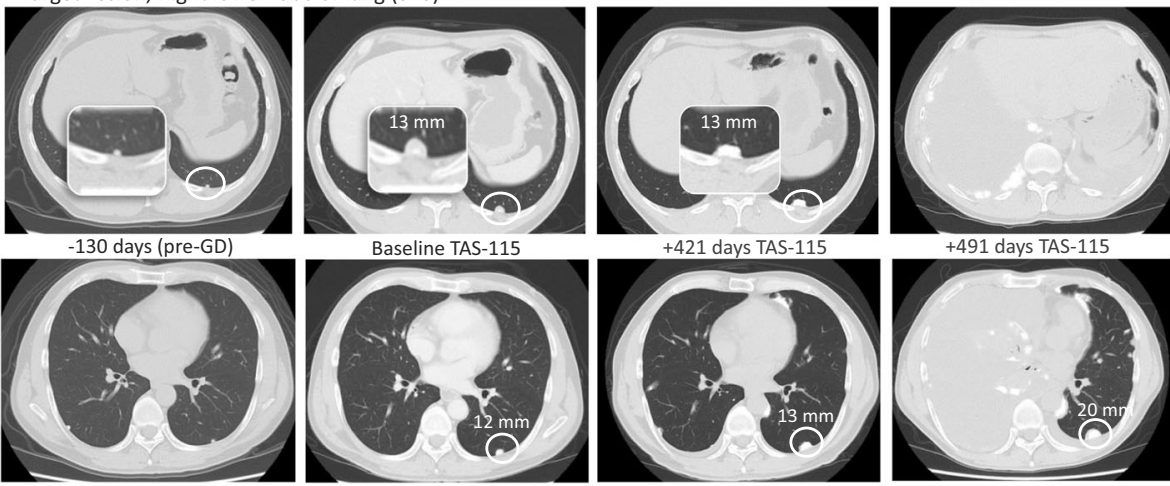

+491 days TAS-115

Target lesion: Right lower lobe of the lung (S6)

C

\#19 Sex: Female Age: 32 years

Primary lesion: Humerus

Metastatic lesion: Lung, bone, LN
Prior therapy

$<1>$ (Neoadjuvant) MTX/CDDP/ADR: 133 days

$<2>$ (Adjuvant) ADR/MTX/IFO: 147 days

$<3>$ GEM+DTX: 43 days
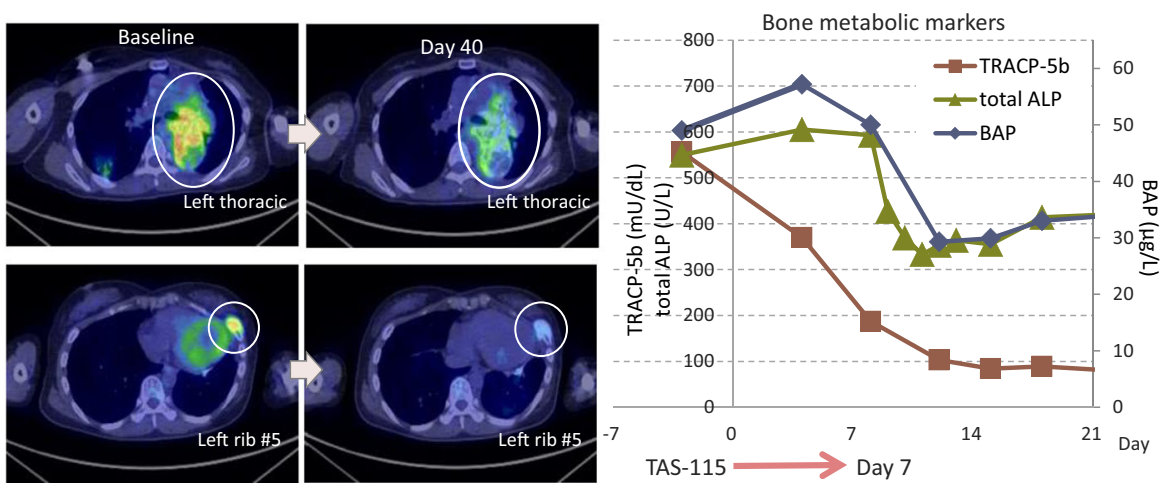

Discontinued due to rash 
The incidence of serious ADRs was $15 \%(n=3)$; these included one case each of enterocolitis, pyrexia, and rash. Eleven $(55 \%)$ patients required a dose reduction and 12 (60\%) patients required a dose interruption due to an ADR (Supplementary Table 2). Of note, one patient (5\%) presented a grade 1 pneumothorax. No deaths occurred due to ADRs.

\section{Efficacy}

The best overall response was SD $(50 \% ; n=10)$; the DCR was $40 \%$. No patient achieved CR/PR. Median PFS was 3 months (95\% CI: 1.6-13.8); 4-month and 12-month progression-free rates (PFR) were $42 \%$ and $31 \%$, respectively (Fig. 1).

Of the eight patients with bone scintigraphy data, six (75\%) had $\geq 30 \%$ BSI reduction (Fig. 2). Supplementary Figure 2 shows the individual change in bone scan response from baseline in the eight patients who underwent bone scintigraphy and indicates the general trend towards BSI reduction over time. Three individual patient cases are described in Fig. 3.

\section{Exposure}

Figure 4 shows the durations of prior treatments and TAS115. In nine (45\%) patients, TAS-115 treatment duration was longer than previous treatment duration. The median TAS-115 treatment duration was 83 days and the mean (standard deviation) relative dose intensity was $65 \%$ (22\%). Sixteen patients $(80 \%)$ discontinued treatment because of disease progression $(n=10 ; 50 \%)$, ADR $(n=3 ; 5 \%)$, and investigator's discretion $(n=1 ; 5 \%)$ (Supplementary Table 2$)$.

\section{Discussion}

In this expansion cohort of an ongoing Phase I study of TAS115 in patients with solid tumours [15], the most common grade $\geq 3$ ADRs with TAS-115 were neutrophil count decreased, white blood cell count decreased, and hypophosphatemia, which was comparable with parts 1, 2, and the expansion cohort of the overall Phase I study [15]. The incidence of grade $\geq 3$ neutropenia and thrombocytopenia related to the study drug in this study was higher than that reported in a previous study of cabozantinib [16]. The higher incidence is possibly because the number of previous treatments in our patients was higher: $90 \%$ of patients received a regimen equivalent to MAP. Additionally, $60 \%$ of patients received at least two regimens as other treatments. The proportions of patients requiring a dose reduction due to neutropenia and thrombocytopenia were $30 \%(n=6)$ and $20 \%(n=$ 4 ), respectively, but the duration of these grade $\geq 3$ ADRs was about 1 week. The incidence of febrile neutropenia among patients was $5 \%(n=1)$. While the incidences of these grade $\geq$ 3 ADRs were higher compared with the previous study of cabozantinib, these ADRs were manageable.

The incidences of dose reductions and interruptions of TAS-115 treatment due to ADRs were 55\% and 60\%, respectively. The incidence of discontinuation due to ADRs was $15 \%$; thus, TAS-115 is tolerable with dose reduction or temporary treatment suspension. Long-term disease control (>1 year) of TAS-115 was achieved in three patients; treatment durations with TAS-115 were longer compared with previous therapeutic regimens in around half of patients, suggesting a possible prolonged exposure to TAS-115.

In terms of TAS-115 efficacy, the PFR after 4 months of TAS-115 treatment was $42 \%$; this was a higher percentage
Fig. 4 Comparison of treatment duration between previous regimens and TAS-115. ADM, adriamycin; CBDCA, carboplatin; CDDP, cisplatin; DTX, docetaxel; GEM, gemcitabine; IFO, ifosfamide; NE, not evaluable; PD, progressive disease; $\mathrm{SD}$, stable disease; VP-16, etoposide

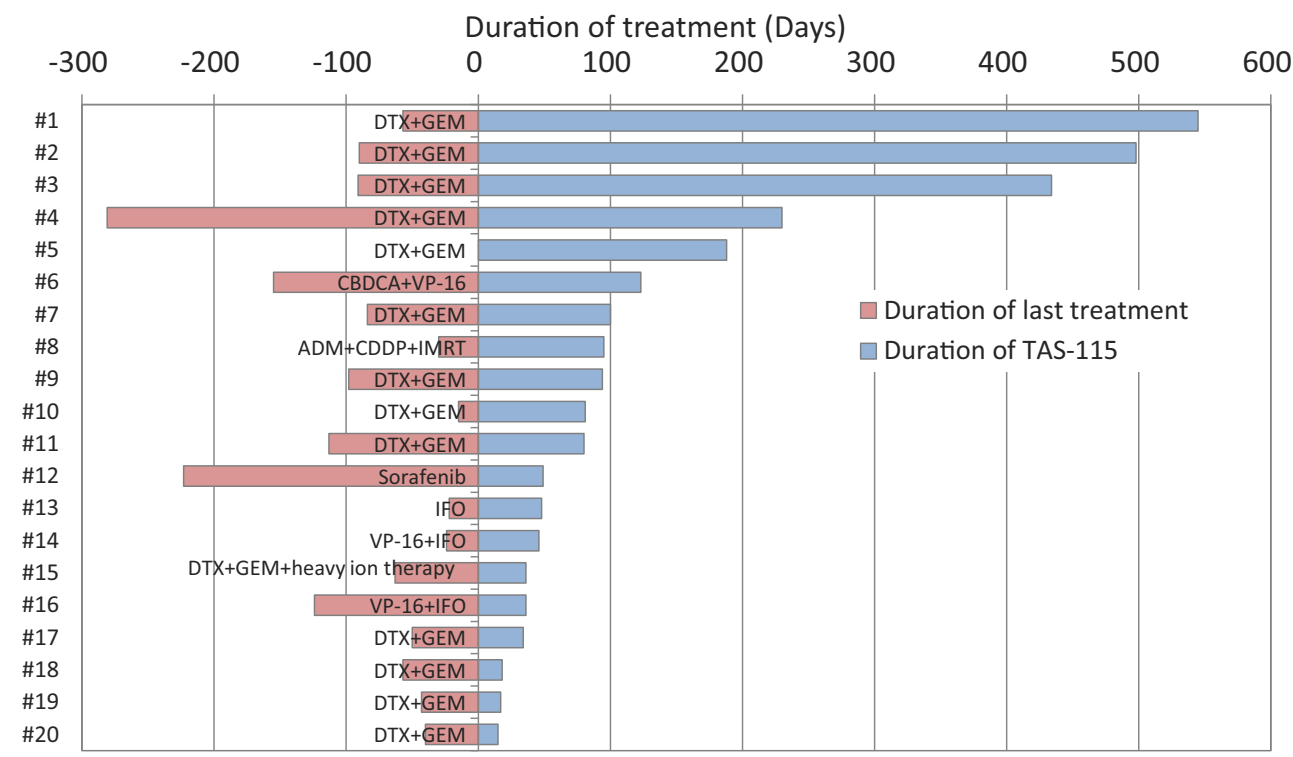


than the 4-month PFR of $12 \%$ reported for osteosarcoma patients in a pooled analysis of seven Phase II, randomised controlled trials of refractory/recurrent paediatric solid tumours using conventional chemotherapy agents [8]. In a recent Phase II study of regorafenib [11], the PFR at 2 months (8 weeks) was $65 \%$. We consider that the difference in PFR compared with the present study stems from differences in the two patient populations: patients in the regorafenib study were at earlier stages of osteosarcoma and had a shorter treatment history (one or two previous lines of treatment). Conversely, a Phase II study of cabozantinib included heavily pretreated patients, and $33.3 \%$ of patients had not progressed by 6 months [12], which is more comparable with our own data.

$\mathrm{CR} / \mathrm{PR}$ was not observed. In 10 out of $20(50 \%)$ patients, SD lasted for extended periods compared with the previous treatment. A recent study reported that $61 \%$ of pulmonary metastases were calcified in osteosarcoma patients [17], and tumour volume shrinkage according to RECIST criteria may not correctly reflect drug efficacy in osteosarcoma.

In this study, we used change in BSI on bone scans as an assessment to evaluate treatment response/benefit. However, we do not consider it feasible to draw conclusions regarding the relationship between BSI, lung CT changes, and efficacy because the number of patients was small and the duration of the assessment was short. To determine whether early changes in BSI can be used as an imaging biomarker for clinical benefit, further investigations are required.

The efficacy of various biologics and small molecules was evaluated in osteosarcoma, yielding far from promising results [18-20] and a lack of improvement in survival rates $[2,7]$. However, inhibition of PDGFR, VEGFR, and MET in non-clinical and clinical studies resulted in antiproliferative effects [21-24]. Mifamurtide, a potent activator of immune response, activates macrophages and monocytes and has shown efficacy in combination with MAP therapy [25]. TAS-115 is expected to exert a similar inhibitory effect and may also suppress the differentiation of M2-like macrophages, involved in cancer-related inflammation, tumour growth, and progression [26], via colony-stimulating factor-1 receptor (CSF-1R) inhibition [27], as well as improve antitumour immune defences in the tumour microenvironment. A case analysis (Fig. 3c) indicated that despite TAS-115 treatment discontinuation after 1 week, PET-CT imaging at 6 weeks confirmed signal attenuation of bone metabolic markers, which we hypothesise may have been due to improved antitumour immune defences in the tumour microenvironment by CSF-1R inhibition.

In conclusion, the safety and tolerability profile in this study and the confirmation of long-term disease stabilization, suggest that TAS-115 is a promising treatment for advanced osteosarcoma. The main study limitations were the open-label, non-comparative design and small sample size, so further clinical investigation of TAS-115 should be conducted in these patients.

Supplementary Information The online version contains supplementary material available at https://doi.org/10.1007/s10637-021-01107-4.

Acknowledgements This work was supported by Taiho Pharmaceutical. The company participated in study design and analysis and interpretation of data. The authors wish to thank patients who participated in this trial and their families, and all the investigators and the members of the Data Monitoring Committee, as well as the coordinators and study site personnel. Additionally, we thank Keyra Martinez Dunn, MD, from Edanz Medical Writing, for providing medical writing services.

Availability of data and materials Data are not available to other researchers for sponsor's policy.

Authors' contributions All the authors: Investigation, Resources, Writing - Review \& Editing. Akira Kawai: Writing - Original Draft, Visualization, Supervision. Norifumi Naka: Supervision. Shunji Takahashi: Supervision. Noboru Yamamoto: Supervision. Toshihiko Doi: Conceptualization, Methodology, Supervision. The author(s) read and approved the final manuscript.

Funding This work was supported by Taiho Pharmaceutical. The company participated in study design and analysis and interpretation of data.

\section{Declarations}

Conflicts of interest/competing interests NN, YI, FN, SI, EK, HO, and HT have nothing to declare.

$\mathrm{AK}$ reports grants and personal fees from Taiho during the conduct of the study; and grants and personal fees from Eisai, Novartis, Takara, Otsuka, and Eli Lilly outside the submitted work.

AS reports grants from Taiho during the conduct of the study; grants and personal fees from AstraZeneca and Chugai; and personal fees from Pfizer, Eli Lilly, Eisai, Mundipharma, Daiichi-Sankyo, and Novartis outside the submitted work.

ST reports grants and personal fees from Taiho during the conduct of the study; and grants and personal fees from Eisai, Novartis, Chugai, Bayer, AstraZeneca, and MSD outside the submitted work.

SK reports grants and personal fees from Boehringer Ingelheim, Eisai, Ono, and REGENERON; personal fees from AstraZeneca, Chugai, Pfizer, Sanofi, Nippon Kayaku, Meiji Seika Pharma, Taiho, Novartis, Daiichi-Sankyo, MSD, Kyowa Hakko Kirin, Celgene, Sumitomo Dainippon Pharma, Bristol-Myers Squibb, AYUMI Pharmaceutical Corporation, Rakuten Medical, PMDA (Pharmaceuticals and Medical Devices Agency), and GSK; and grants from Astellas, Gilead Sciences, AMED (Japan Agency for Medical Research and Development), and JSPS (Japan Society for the Promotion of Science) outside the submitted work.

KY reports personal fees from Taiho, Pfizer, AstraZeneca, Eisai, Novartis, Ono, and Chugai outside the submitted work.

YN reports speaker's bureau fees from Pfizer, Taiho, Nippon Kayaku, Eli Lilly, AstraZeneca, Merck Serono, Bayer, Meiji Seika Pharma, Roche Diagnostics, Novartis, Chugai, and Eisai outside the submitted work.

NY reports grants and personal fees from Ono, Chugai, Pfizer, Eli Lilly, BMS, Eisai, Takeda, and Boehringer Ingelheim; grants from Taiho, Quintiles, Astellas, BMS, Novartis, Daiichi-Sankyo, Kyowa-Hakko 
Kirin, Bayer, Janssen Pharma, MSD, Merck, and GSK; and personal fees from AstraZeneca, Otsuka, Cimic, and Sysmex outside the submitted work.

TD reports grants and personal fees from Lilly, Kyowa Hakko Kirin, MSD, Daiichi-Sankyo, Sumitomo Dainippon, Taiho, Novartis, Boehringer Ingelheim, Chugai, Bristol-Myers Squibb, and Abbvie; grants from Merck Serono, Janssen, Pfizer, Quintiles, and Eisai; and personal fees from Amgen, Takeda, Bayer, Rakuten Medical, Ono, Astellas Pharma, and Oncolys BioPharma outside the submitted work.

Ethics approval The study protocol was approved by the institutional review board at each participating site and was conducted per the ethical principles of the Declaration of Helsinki, Pharmaceutical Affairs Law, and Good Clinical Practice.

Consent to participate All patients provided written informed consent prior to their inclusion in the study.

Collaborators The authors have no collaborators to declare.

Open Access This article is licensed under a Creative Commons Attribution 4.0 International License, which permits use, sharing, adaptation, distribution and reproduction in any medium or format, as long as you give appropriate credit to the original author(s) and the source, provide a link to the Creative Commons licence, and indicate if changes were made. The images or other third party material in this article are included in the article's Creative Commons licence, unless indicated otherwise in a credit line to the material. If material is not included in the article's Creative Commons licence and your intended use is not permitted by statutory regulation or exceeds the permitted use, you will need to obtain permission directly from the copyright holder. To view a copy of this licence, visit http://creativecommons.org/licenses/by/4.0/.

\section{References}

1. Mirabello L, Troisi RJ, Savage SA (2009) International osteosarcoma incidence patterns in children and adolescents, middle ages and elderly persons. Int J Cancer 125(1):229-234. https://doi.org/10. 1002/ijc. 24320

2. Lindsey BA, Markel JE, Kleinerman ES (2017) Osteosarcoma Overview. Rheumatol Ther 4(1):25-43. https://doi.org/10.1007/ s40744-016-0050-2

3. Harrison DJ, Geller DS, Gill JD, Lewis VO, Gorlick R (2018) Current and future therapeutic approaches for osteosarcoma. Expert Rev Anticancer Ther 18(1):39-50. https://doi.org/10.1080/ 14737140.2018.1413939

4. Casali PG, Bielack S, Abecassis N, Aro HT, Bauer S, Biagini R, Bonvalot S, Boukovinas I, Bovee J, Brennan B, Brodowicz T, Broto JM, Brugières L, Buonadonna A, De Álava E, Dei Tos AP, Del Muro XG, Dileo P, Dhooge C, Eriksson M, Fagioli F, Fedenko A, Ferraresi V, Ferrari A, Ferrari S, Frezza AM, Gaspar N, Gasperoni S, Gelderblom H, Gil T, Grignani G, Gronchi A, Haas RL, Hassan B, Hecker-Nolting S, Hohenberger P, Issels R, Joensuu H, Jones RL, Judson I, Jutte P, Kaal S, Kager L, Kasper B, Kopeckova K, Krákorová DA, Ladenstein R, Le Cesne A, Lugowska I, Merimsky O, Montemurro M, Morland B, Pantaleo MA, Piana R, Picci P, Piperno-Neumann S, Pousa AL, Reichardt P, Robinson MH, Rutkowski P, Safwat AA, Schöffski P, Sleijfer S, Stacchiotti S, Strauss SJ, Sundby Hall K, Unk M, Van Coevorden F, van der Graaf WTA, Whelan J, Wardelmann E, Zaikova O, Blay JY (2018) Bone sarcomas: ESMO-PaedCan-EURACAN clinical practice guidelines for diagnosis, treatment and follow-up. Ann
Oncol 29(Suppl 4):iv79-iv95. https://doi.org/10.1093/annonc/ mdy 310

5. Gok Durnali A, Paksoy Turkoz F, Ardic Yukruk F, Tokluoglu S, Yazici OK, Demirci A, Bal O, Gundogdu Buyukbas S, Esbah O, Oksuzoglu B, Alkis N (2016) Outcomes of adolescent and adult patients with lung metastatic osteosarcoma and comparison of synchronous and Metachronous lung metastatic groups. PLoS One 11(5):e0152621. https://doi.org/10.1371/journal.pone.0152621

6. Walters DK, Steinmann P, Langsam B, Schmutz S, Born W, Fuchs B (2008) Identification of potential chemoresistance genes in osteosarcoma. Anticancer Res 28(2a):673-679

7. Berner K, Johannesen TB, Berner A, Haugland HK, Bjerkehagen B, Bøhler PJ, Bruland ØS (2015) Time-trends on incidence and survival in a nationwide and unselected cohort of patients with skeletal osteosarcoma. Acta Oncol 54(1):25-33. https://doi.org/ 10.3109/0284186x.2014.923934

8. Lagmay JP, Krailo MD, Dang H, Kim A, Hawkins DS, Beaty O 3rd, Widemann BC, Zwerdling T, Bomgaars L, Langevin AM, Grier HE, Weigel B, Blaney SM, Gorlick R, Janeway KA (2016) Outcome of patients with recurrent osteosarcoma enrolled in seven phase II trials through Children's Cancer group, pediatric oncology group, and Children's oncology group: learning from the past to move forward. J Clin Oncol 34(25):3031-3038. https://doi.org/10. 1200/jco.2015.65.5381

9. Tsuchiya H, Kanazawa Y, Abdel-Wanis ME, Asada N, Abe S, Isu K, Sugita T, Tomita K (2002) Effect of timing of pulmonary metastases identification on prognosis of patients with osteosarcoma: the Japanese musculoskeletal oncology group study. J Clin Oncol 20(16):3470-3477. https://doi.org/10.1200/jco.2002.11.028

10. Kansara M, Teng MW, Smyth MJ, Thomas DM (2014) Translational biology of osteosarcoma. Nat Rev Cancer 14(11): 722-735. https://doi.org/10.1038/nrc3838

11. Duffaud F, Mir O, Boudou-Rouquette P, Piperno-Neumann S, Penel N, Bompas E, Delcambre C, Kalbacher E, Italiano A, Collard O, Chevreau C, Saada E, Isambert N, Delaye J, Schiffler C, Bouvier C, Vidal V, Chabaud S, Blay JY (2019) Efficacy and safety of regorafenib in adult patients with metastatic osteosarcoma: a non-comparative, randomised, double-blind, placebo-controlled, phase 2 study. Lancet Oncol 20(1):120-133. https://doi.org/10. 1016/s1470-2045(18)30742-3

12. Italiano A (2018) Cabozantinib in patients with advanced osteosarcomas and Ewing sarcomas. Presented at the European Society for Medical Oncology congress 2018, Munich https://cslide. ctimeetingtech.com/esmo2018/public/download_uploaded_media/ pdf/226. Accessed 20 Feb 2020

13. Fujita H, Gomori A, Fujioka Y, Kataoka Y, Tanaka K, Hashimoto A, Suzuki T, Ito K, Haruma T, Yamamoto-Yokoi H, Harada N, Sakuragi M, Oda N, Matsuo K, Inada M, Yonekura K (2016) High potency VEGFRs/MET/FMS triple blockade by TAS-115 concomitantly suppresses tumor progression and bone destruction in tumor-induced bone disease model with lung carcinoma cells. PLoS One 11(10):e0164830. https://doi.org/10.1371/journal.pone. 0164830

14. Fujita H, Miyadera K, Kato M, Fujioka Y, Ochiiwa H, Huang J, Ito K, Aoyagi Y, Takenaka T, Suzuki T, Ito S, Hashimoto A, Suefuji T, Egami K, Kazuno H, Suda Y, Nishio K, Yonekura K (2013) The novel VEGF receptor/MET-targeted kinase inhibitor TAS-115 has marked in vivo antitumor properties and a favorable tolerability profile. Mol Cancer Ther 12(12):2685-2696. https://doi.org/10. 1158/1535-7163.Mct-13-0459

15. Doi T, Matsubara N, Kawai A, Naka N, Takahashi S, Uemura H, Yamamoto N (2020) Phase I study of TAS-115, a novel oral multikinase inhibitor, in patients with advanced solid tumors. Investig New Drugs 38(4):1175-1185. https://doi.org/10.1007/s10637-01900859-4 
16. Italiano A, Mir O, Mathoulin-Pelissier S, Penel N, PipernoNeumann S, Bompas E, Chevreau C, Duffaud F, Entz-Werlé N, Saada E, Ray-Coquard I, Lervat C, Gaspar N, Marec-Berard P, Pacquement H, Wright J, Toulmonde M, Bessede A, Crombe A, Kind M, Bellera C, Blay JY (2020) Cabozantinib in patients with advanced Ewing sarcoma or osteosarcoma (CABONE): a multicentre, single-arm, phase 2 trial. Lancet Oncol 21(3):446455. https://doi.org/10.1016/S1470-2045(19)30825-3

17. Ciccarese F, Bazzocchi A, Ciminari R, Righi A, Rocca M, Rimondi E, Picci P, Bacchi Reggiani ML, Albisinni U, Zompatori M, Vanel D (2015) The many faces of pulmonary metastases of osteosarcoma: retrospective study on 283 lesions submitted to surgery. Eur J Radiol 84(12):2679-2685. https://doi.org/10.1016/j.ejrad.2015.09. 022

18. Ebb D, Meyers P, Grier H, Bernstein M, Gorlick R, Lipshultz SE, Krailo M, Devidas M, Barkauskas DA, Siegal GP, Ferguson WS, Letson GD, Marcus K, Goorin A, Beardsley P, Marina N (2012) Phase II trial of trastuzumab in combination with cytotoxic chemotherapy for treatment of metastatic osteosarcoma with human epidermal growth factor receptor 2 overexpression: a report from the children's oncology group. J Clin Oncol 30(20):2545-2551. https:// doi.org/10.1200/jco.2011.37.4546

19. Burrow S, Andrulis IL, Pollak M, Bell RS (1998) Expression of insulin-like growth factor receptor, IGF-1, and IGF-2 in primary and metastatic osteosarcoma. J Surg Oncol 69(1):21-27. https:// doi.org/10.1002/(sici)1096-9098(199809)69:1<21::aid-jso5>3.0. co;2-m

20. Pappo AS, Vassal G, Crowley JJ, Bolejack V, Hogendoorn PC, Chugh R, Ladanyi M, Grippo JF, Dall G, Staddon AP, Chawla SP, Maki RG, Araujo DM, Geoerger B, Ganjoo K, Marina N, Blay JY, Schuetze SM, Chow WA, Helman LJ (2014) A phase 2 trial of R1507, a monoclonal antibody to the insulin-like growth factor-1 receptor (IGF-1R), in patients with recurrent or refractory rhabdomyosarcoma, osteosarcoma, synovial sarcoma, and other soft tissue sarcomas: results of a sarcoma Alliance for research through collaboration study. Cancer 120(16):2448-2456. https:// doi.org/10.1002/cncr.28728

21. Grignani G, Palmerini E, Dileo P, Asaftei SD, D'Ambrosio L, Pignochino Y, Mercuri M, Picci P, Fagioli F, Casali PG, Ferrari
S, Aglietta M (2012) A phase II trial of sorafenib in relapsed and unresectable high-grade osteosarcoma after failure of standard multimodal therapy: an Italian sarcoma group study. Ann Oncol 23(2): 508-516. https://doi.org/10.1093/annonc/mdr151

22. Tanaka T, Yui Y, Naka N, Wakamatsu T, Yoshioka K, Araki N, Yoshikawa H, Itoh K (2013) Dynamic analysis of lung metastasis by mouse osteosarcoma LM8: VEGF is a candidate for antimetastasis therapy. Clin Exp Metastasis 30(4):369-379. https:// doi.org/10.1007/s10585-012-9543-8

23. Safwat A, Boysen A, Lücke A, Rossen P (2014) Pazopanib in metastatic osteosarcoma: significant clinical response in three consecutive patients. Acta Oncol 53(10):1451-1454. https://doi.org/ 10.3109/0284186x.2014.948062

24. Dani N, Olivero M, Mareschi K, van Duist MM, Miretti S, Cuvertino S, Patané S, Calogero R, Ferracini R, Scotlandi K, Fagioli F, Di Renzo MF (2012) The MET oncogene transforms human primary bone-derived cells into osteosarcomas by targeting committed osteo-progenitors. J Bone Miner Res 27(6):1322-1334. https://doi.org/10.1002/jbmr.1578

25. Meyers PA, Schwartz CL, Krailo M, Kleinerman ES, Betcher D, Bernstein ML, Conrad E, Ferguson W, Gebhardt M, Goorin AM, Harris MB, Healey J, Huvos A, Link M, Montebello J, Nadel H, Nieder M, Sato J, Siegal G, Weiner M, Wells R, Wold L, Womer R, Grier H (2005) Osteosarcoma: a randomized, prospective trial of the addition of ifosfamide and/or muramyl tripeptide to cisplatin, doxorubicin, and high-dose methotrexate. J Clin Oncol 23(9): 2004-2011. https://doi.org/10.1200/jco.2005.06.031

26. Mantovani A, Sozzani S, Locati M, Allavena P, Sica A (2002) Macrophage polarization: tumor-associated macrophages as a paradigm for polarized M2 mononuclear phagocytes. Trends Immunol 23(11):549-555. https://doi.org/10.1016/s1471-4906(02)02302-5

27. Hamilton JA (2008) Colony-stimulating factors in inflammation and autoimmunity. Nat Rev Immunol 8(7):533-544. https://doi. org/10.1038/nri2356

Publisher's note Springer Nature remains neutral with regard to jurisdictional claims in published maps and institutional affiliations. 